SJ Quinney College of Law, University of Utah Utah Law Digital Commons

Wallace Stegner Center for Land, Resources, and the Environment publications

2016

NEPA-Substantive Effectiveness Under a Procedural Mandate: Assessment of Oil and Gas EISs in the Mountain West

John C. Ruple

Mark Capone

Follow this and additional works at: https://dc.law.utah.edu/stegner_pubs

Part of the Environmental Law Commons, and the Natural Resources Law Commons 


\title{
NEPA-Substantive Effectiveness Under a Procedural Mandate: Assessment of Oil and Gas EISs in the Mountain West
}

\author{
John Ruple* and Mark Capone**
}

\section{Introduction}

\section{A. Project Overview}

This Article empirically evaluates whether the National Environmental Policy Act ("NEPA") ${ }^{1}$ is effective in reducing environmental impacts for oil and natural gas development projects. "Effectiveness" is defined here as a significant reduction in impacts anticipated between the initial proposal and the project as approved following completion of an Environmental Impact Statement ("EIS").

NEPA requires federal agencies to prepare an environmental statement for "major Federal actions significantly affecting the quality of the human environment." ${ }^{2}$ NEPA's procedural mandate does not require federal agencies to

* Research Associate Professor of Law, Wallace Stegner Center for Land, Resources \& the Environment, S.J. Quinney College of Law at the University of Utah.

** J.D., University of Utah; M.S., University of New Hampshire.

The Authors would like to thank the $444 S$ Foundation, the Natural Resources Defense Council, the Partnership Project, and the AHEI CI Trust for funding this research effort. The Authors would also like to thank Professors Robin Craig, Arnold Reitze, and Robert Keiter from the University of Utah's S.J. Quinney College of Law for their careful review of, and thoughtful comments on, drafts of this Article. The Authors are also grateful to Seth Latimer, Senior Research Analyst at the University of Utah's College of Nursing, and Jason L. Jones, Ecologist/Herpetologist with the Nevada Department of Wildlife, for their review and assistance with the statistical analysis contained herein. The Authors, however, are solely responsible for the opinions, recommendations, and any errors or omissions contained herein. Furthermore, the views and opinions expressed herein do not necessarily reflect those of the United States Government or any agency thereof, or of any funding entity.

1. National Environmental Policy Act of 1969, Pub. L. No. 91-190, 83 Stat. 852 (1970) (codified as amended at 42 U.S.C. $\$ \$ 4321-4347$ (2012)).

2. 42 U.S.C. $\$ 4332(2)(\mathrm{C})$. select the least environmentally damaging alternative, but, rather, to take a "hard look" at the environmental impacts of alternative courses of action before making a decision. ${ }^{3}$ Indeed, "[i]f the adverse environmental effects of the proposed action are adequately identified and evaluated, the agency is not constrained by NEPA from deciding that other values outweigh the environmental costs." ${ }^{\prime 4}$

Because NEPA is a procedural law, scholars have focused primarily on assessing procedural efficiencies in the decision-making process. ${ }^{5}$ Accordingly, as the U.S. Government Accountability Office ("GAO") recently noted, "[i]nformation on the benefits of completing NEPA analyses is largely qualitative." Moreover, as the GAO explained, "agency activities under NEPA are hard to separate from other environmental review tasks under federal laws, such as the Clean Water $\mathrm{Act}^{7}$ and the Endangered Species Act; ${ }^{8}$ executive orders; agency guidance; and state and local laws."

While there is little scholarship testing NEPA's substantive effectiveness, there is a growing body of research conducted on NEPA analogs in other countries. ${ }^{10}$ More than 100 countries have emulated NEPA and require some sort of environmental assessment process for certain projects. ${ }^{11}$ Consequently, a number of studies have evaluated the sub-

3. Marsh v. Or. Nat. Res. Council, 490 U.S. 360, 374 (1989).

4. Robertson v. Methow Valley Citizens Council, 490 U.S. 332, 350 (1989).

5. Daniel R. Mandelker, NEPA Law and Litigation $\$ 11: 1$ (2d ed. 2014).

6. U.S. Gov't Accountability Office, GAO-14-370, National Environmental Policy Act: Little Information Exists on NEPA Analyses 11 (2014); see also MANDELKER, supra note 5.

7. Clean Water Act of 1977, Pub. L. No. 95-217, 91 Stat. 1566 (codified as amended at 33 U.S.C. $\$ \$ 1251-1387$ (2012)).

8. Endangered Species Act of 1973, Pub. L. No. 93-205, 87 Stat. 884 (codified as amended at 16 U.S.C. $\$ \$ 1531-1544$ (2012)).

9. U.S. Gov't Accountability Office, supra note 6 (internal citations added).

10. Mathew Cashmore et al., The Interminable Issue of Effectiveness: Substantive Purposes, Outcomes and Research Challenges in the Advancement of Environmental Impact Assessment Theory, 22 Envtl. Assessment \& Project Appraisal 295, 299-301 (2004).

11. Mathew Cashmore et al., The Role and Functioning of Environment Assessment: Theoretical Reflections Upon an Empirical Investigation of Causation, $88 \mathrm{~J}$. ENvtr. Mgmt. 1233, 1233 (2008). 
stantive effectiveness of these other environmental assessment processes. ${ }^{12}$ Cashmore et al. (2004), in summarizing these studies, found that it was difficult to generalize regarding the substantive effect of environmental assessments because of "differences in research methodologies, varying interpretations of [substantive effectiveness], and . . . restricted geographical spread . . . ."13 However, the studies reviewed in Cashmore et al. (2004) indicated that environmental assessments did result in moderate project modifications, usually accomplished through "fine tuning" of project proposals to mitigate for or avoid environmental impacts. ${ }^{14}$ We suspect that EISs provide similar benefits by "fine tuning" major federal actions.

This Article advances the debate over NEPA's benefits and what, if any, NEPA reforms would be most valuable. This research is timely because multiple pending bills before Congress propose to "streamline" NEPA by limiting public comment opportunities, limiting the scope of alternatives analyzed, limiting the depth of review, accelerating the timeline for NEPA analysis, or limiting administrative or judicial review. ${ }^{15}$ Understanding whether NEPA leads to less impactful decisions or fewer constrains on economic activity are important factors in weighing the merits of these proposals.

\section{B. NEPA Overview}

NEPA is described as the Magna Carta of environmental laws ${ }^{16}$ and has inspired numerous countries to adopt their own NEPA analogues. ${ }^{17}$ NEPA declares that it is a national policy to "encourage productive and enjoyable harmony between man and his environment; to promote efforts which will prevent or eliminate damage to the environment and biosphere and stimulate the health and welfare of man; [and] to enrich the understanding of the ecological systems and natural resources important to the Nation. . . ." NEPA's lofty policy goals are met through a procedural requirement that federal agencies identify and analyze impacts on the environment prior to taking, authorizing, or funding major federal actions. ${ }^{19}$ Careful consideration, it is believed, will lead to better environmental outcomes.

Under NEPA, "major federal actions significantly affecting the quality of the human environment" must undergo an environmental review prior to federal authorization or fund-

12. Cashmore et al., supra note 10 , at 300-01.

13. Id. at 299.

14. Id. at 299,302 .

15. See, e.g., H.R. 2647, 114th Cong. (2015) (expediting NEPA for forest and timber management activities); S. 468, 114th Cong. (2015) (categorically excluding certain vegetation treatments from NEPA analysis); H.R. 348, 113th Cong. (2015) (establishing procedures to streamline the regulatory review, environmental decisionmaking, and permitting process for construction activities undertaken, reviewed, or funded by federal agencies); H.R. 1616, 114th Cong. (2015) (creating categorical exclusions for certain natural gas development related activities); H.R. 1792, 114th Cong. (2015) (delegating to the states NEPA compliance responsibilities for livestock grazing authorizations).

16. Mandelker, supra note $5, \$ 1: 1$.

17. Bradley C. Karkkainen, Toward a Smarter NEPA: Monitoring and Managing Government's Environmental Performance, 102 Colum. L. Rev. 903, 905 (2002).

18. 43 U.S.C. $\$ 4321(2012)$

19. Id. $\$ 4332(2)(\mathrm{C})(2012)$. ing. ${ }^{20}$ When a major federal project's impacts are known to be significant, compliance requires completion of an EIS. ${ }^{21}$ Completion of an EIS can take several years and cost millions of dollars. ${ }^{22}$ While EISs are required for less than $1 \%$ of projects evaluated under NEPA, ${ }^{23}$ EISs receive more attention than less extensive compliance documents because they involve "high-profile, complex, and expensive" projects. ${ }^{24}$

EISs are prepared in stages. At the outset of the NEPA process, the lead agency publishes a Notice of Intent to Prepare an EIS ("NOI") in the Federal Register. ${ }^{25}$ The NOI describes the action contemplated and invites public comment. After receiving and considering public comment, the lead agency prepares a draft EIS analyzing the direct, indirect, and cumulative impacts of the proposed action, along with alternative means of achieving the purpose and need for the proposed action. ${ }^{26}$ The public is invited to review the draft EIS and provide comments, which the agency reviews and considers, responding as appropriate and revising the NEPA document as needed before issuing the final EIS. ${ }^{27}$

If significant deficiencies are identified, the lead agency may prepare and release a revised draft EIS or a supplemental EIS. ${ }^{28}$ The NEPA process concludes with publication of a Record of Decision ("ROD”) documenting the agency's final decision. ${ }^{29}$ The public is then provided an opportunity to review the ROD and pursue either an administrative appeal or litigation. ${ }^{30}$

Because environmental impacts are normally quantified at each phase of the NEPA process, evaluation of iterative changes between each phase may provide an indicator of the benefits obtained from NEPA review. Significant environmental impact reductions would indicate NEPA efficacy, and whether impacts that are subject to regulation independent of NEPA are reduced more rapidly than those that are not regulated independently, may provide insight into the underlying cause of impact reductions.

\section{Methods}

In designing this project, we sought to answer several questions: (1) Are final NEPA decisions likely to have lower environmental impacts than the initial proposal? (2) What are the economic implications of impact reductions? (3) If iterative changes occurring through the NEPA process lead to a less impactful project, at what stage in the process do most

20. Id.

21. 40 C.F.R. $\$ 1502.3(2014)$.

22. U.S Gov't Accountability Office, supra note 6, at 13-15; Piet deWitt \& Carole A. deWitt, Preparation Times for Final Environmental Impact Statements Made Available From 2007 Through 2010, 10 Envtl. Prac. 123, 125 (2013) [hereinafter deWitt \& deWitt, Preparation Time]; Piet deWitt \& Carole A. deWitt, How Long Does It Take to Prepare an Environmental Impact Statement?, 10 Envtl. Prac. 164, 168 (2008) [hereinafter deWitt \& deWitt, How Long Does It Take?].

23. U.S. Gov't Accountability Office, supra note 6, at 8.

24. Id.

25. 40 C.F.R. $\$ \$ 1501.7,1508.22(2014)$.

26. Id. $\$ \$ 1502.14-1502.16(2014)$.

27. Id. $\$ \$ 1503.1,1503.4(2014)$

28. Id. $\$ 1502.9(\mathrm{a}),(\mathrm{c})(2014)$.

29. Id. $\$ 1505.2$ (2014).

30. Id. $\$ 1505.1$ (2014). 
reductions occur? (4) Is that reduction attributable to NEPA, intervening factors, or a combination of both? (5) Is there a relationship between the number of alternatives considered in an EIS and the amount of environmental impact reduction that occurred through the NEPA process?

Answering these questions is complicated by the tremendous variability in NEPA content, making comparison across projects difficult. This difficulty is a reflection of the breadth of projects subject to NEPA. NEPA's implementing regulations also, necessarily, avoid one-size-fits-all disclosures in favor of an analysis that is meaningful in the context of each proposed action. NEPA regulations, therefore, direct agencies to "identify significant environmental issues deserving of study ... [and] deemphasize insignificant issues, narrowing the scope of the environmental impact statement process accordingly." ${ }^{31}$ Because the NEPA process is intended to be flexible enough to address diverse local conditions and issues, NEPA documents may also measure or model similar impacts in different ways. One NEPA document may, for example, disclose direct employment impacts by year, while another may combine direct and indirect employment into a single value disclosed for the life of the project. ${ }^{32}$ While both approaches are consistent with NEPA's objectives, this lack of uniformity can complicate efforts to compare projects.

In testing the efficacy of NEPA, the conducted research focused on EISs because of their iterative approach, the extensive analysis and documentation they contain, the importance of the decisions they consider, the time and expense involved in EIS preparation, and the controversy often surrounding the projects that require the submission of an EIS. To maximize consistency of impact measures, we focused our analysis on EISs for oil, natural gas, or coalbed methane (collectively "O\&G") development authorized by the U.S. Bureau of Land Management ("BLM") and occurring in Colorado, Montana, Utah, or Wyoming $(n=13)$. Including draft, final, and supplemental EISs, these projects produced a total of forty records. This Article focused on O\&G projects because they involve discrete and easily quantifiable impacts, such as the acres of surface disturbance, the miles of road and pipeline constructed, and the number of wells drilled. These four states were chosen because the large amount of federally managed public lands in this area results in a higher number of recently completed EISs for O\&G projects than was found in other regions.

EISs satisfying the selection criteria were identified by using the U.S. Environmental Protection Agency's EIS Database. ${ }^{33}$ Database coverage begins in January 2004, which provides the starting point for our analysis. We considered all NEPA projects completed (projects which resulted in the publication of a ROD) through October 2014. Even with this narrow scope, there was a great deal of variability between EISs, apparently driven by local conditions and concerns, as well as by differences, in field office procedure.

31. Id. $\$ 1500.4(\mathrm{~g})(2014)$.

32. Id. $\$ 1508.25$ (c) (2014).

33. Environmental Impact Statement (EIS) Database, U.S. Envtl. Protection AgENCY, http://www.epa.gov/compliance/nepa/eisdata.html (last visited Aug. 3, 2015).
We obtained and reviewed every NOI, draft EIS, final EIS, supplemental EIS (if any), and ROD for each project meeting our selection requirements. Impact metrics associated with the proposed action in the draft EIS, preferred alternatives in the final EIS, and agency decisions contained in the ROD were recorded. Consistent with deWitt and deWitt (2008), we also recorded document release dates, ${ }^{34}$ as well as the number of alternatives considered in each document. A complete set of the impact metrics that were identified and recorded is listed in Table 1. Metrics shown in italics failed to meet minimum sample size requirements and were not carried forward for statistical analysis. We initially speculated that NOIs might contain key indicators, such as the number of wells proposed, hence providing an additional data point, but there was insufficient information available to make most NOIs a meaningful indicator of anticipated project impact or benefit.

Statistical analysis was limited to variables that were reported in at least eight of the thirteen EISs. Where necessary to facilitate comparison and meet minimum sample size requirements, agency-provided data was converted into a consistent metric. As an example, some EISs calculated water use per year and others calculated water use for the life of the project. To create a common metric, we converted water use per year to water use for the life of the project by multiplying yearly water use by the agency's estimated project life.

Economic measures (hydrocarbon production, jobs created, and tax revenue generated) were reported with less consistency than environmental measures, creating a challenge to capturing NEPA's economic consequences. Hydrocarbon production, for example, represents an obvious indicator of commodity production. However, only three EISs estimated natural gas extraction, only four EISs estimated both gas and oil extraction, and five EISs did not estimate oil or gas extraction at all. We attempted to overcome this problem by converting volumetric O\&G extraction data into British thermal units. However, even with this conversion, we failed to satisfy our minimum sample size requirements, preventing us from effectively analyzing resource production. We instead focused on state and local tax revenues $(n=9)$ and oil and gas related jobs $(n=13)$ as common measures of economic impact.

This design allows comparison of the environmental and economic impact indicators for a project at three stages. To determine whether and when NEPA influences these indicators, we compared the draft EIS proposed action, the final EIS agency preferred action, and the ROD selected action. We used single-tailed paired t-tests to determine whether impacts changed significantly throughout the process. ${ }^{35}$ The paired t-test is appropriate because we are comparing data from the same EISs but at different stages of the processthe draft EIS, final EIS, and ROD. ${ }^{36}$ Pairing helped reduce the variance in the results caused by different initial project

34. deWitt \& deWitt, How Long Does It Take?, supra note 22, at 165.

35. The single-tail reflects our initial hypothesis that NEPA would reduce environmental impacts and economic benefits. See generally Dawn Hawkins, Biomeasurement: A Student's Guide to Biostatistics 80 (3d ed. 2014).

36. See id. at 143 . 
size. The single-tail reflects our initial hypothesis that NEPA would reduce environmental impacts and economic benefits. To better describe when project changes occur in the process, we calculated the percentage of the total reduction that occurred for each impact at the final EIS and ROD stage.

We also sought to determine how the number of alternatives affected environmental impact reduction. First, we conducted a regression analysis to determine whether any of the initially proposed impact factors predicted the number of alternatives considered by the agency. Second, we conducted a regression analysis to determine whether the number of alternatives considered predicted impact reductions.

To determine whether EISs with more alternatives resulted in significantly higher impact reduction than EISs with less alternatives, O\&G EISs were separated into two groups-the More Alternatives Group and the Fewer Alternatives Group. First, we determined the average number of alternatives considered in the thirteen final EISs. Next, we created one group for EISs that considered the average number of alternatives or more and a second group that considered less than the average. We then determined the total reduction for each impact, as measured by the difference in an impact between the draft EIS and the ROD, for each of the two groups. Lastly, we tested whether the More Alternatives Group resulted in a statistically significant difference in impact reduction using single-tailed t-tests. ${ }^{37}$ We also calculated impact reduction as a percentage of the initial draft EIS impact measure. We include percentage information because of the potential relationship between the size of initial draft EIS impacts and the number of alternatives considered. ${ }^{38}$

We selected our impact metrics based on four factors; we looked for indicators that: (1) addressed a range of impact areas (air, water, land, and economic); (2) were quantified using common units of measure or units that could be converted into a common measure; (3) were utilized in all or almost all of the EISs; and (4) provided a balance between

37. The single-tailed t-tests reflect our initial hypothesis that more alternatives will result in greater impact reductions.

38. If the number of alternatives considered is positively related to the initial impacts in the draft EIS, then we would expect agencies to consider fewer alternatives for projects with smaller impacts and more alternatives for projects with larger impacts. In this case, any impact reduction difference between our two groups might have been caused by differences in initial impacts. For example, the More Alternatives Group may have greater gross impact reduction relative to the Fewer Alternatives Group simply because there were more initial impacts. We use percentage reduction purely as a descriptive statistic, as percentage reduction partially controls for the confounding variable of initial impact size by showing impact reduction as a proportion of the initial impact. We did not test for statistical significance using our percent change values because of problems inherent to statistical analysis of percentages. See Andrew J. Vickers, The Use of Percentage Change From Baseline as an Outcome in a Controlled Trial Is Statistically Inefficient: A Simulation Study, 1 BMC Med. Res. MethodolOGY 1, 5 (2001) (suggesting the use of an Analysis of Covariance model and cautioning that "[p]ercentage change from baseline should therefore not be used in statistical analysis"). Because of our low sample size and unequal samples between groups (one group had a sample size of four and the other group nine), an Analysis of Covariance was inappropriate for our data. See generally Robert J. Grissom \& Jon J. Kim, Effect Sizes for Research: Univariate and Multivariate Analysis 352 ( $2 \mathrm{~d}$ ed. 2012) (stating Analysis of Covariance is generally inappropriate for unequal sample sizes); Marjorie A. РetT, Nonparamtetric Statistics for Health Care Research: Statistics for Small Sample Sizes and Unusual Distributions 56 (1997) (stating that unequal and small sample sizes render some statistical analysis impossible).

\section{Table I Impact Metrics}

\author{
Number of wells and well pads \\ Amount of surface disturbance: \\ - temporary, \\ - permanent, and \\ - wetlands \\ Air emissions: \\ - PMIO, \\ - PM2.5, \\ - NOX, \\ - SO2, and \\ - CO \\ Miles of road and pipeline constructed \\ Volume of water used \\ Volume of oil and natural gas produced* \\ Amount of tax revenue generated by state and local governments \\ Number of jobs created \\ Project cost*
}

* Metrics that were not analyzed statistically because of sample size constraints

indicators that are subject to independent statutory or regulatory mandates to minimize impacts and indicators that are not independently regulated. The fourth criteria is important in determining whether impacts between these two groups were reduced at similar rates. This, in turn, provides insight into the driving factors behind impact reduction.

The amount of water utilized and surface disturbance are used as broad indicators of environmental impact. Water use, however, may understate efforts to reduce water consumption, as efficiency improvements may be offset by water used for directional drilling and improved hydraulic fracturing which, as explained below, may lead to large reductions in surface disturbance. Such tradeoffs are inherent in the NEPA decision-making process, where reducing impacts to sensitive resources may necessitate an increase in impacts elsewhere. We distinguish between temporary and permanent impacts to maintain consistency with EIS disclosures. We track wetland disturbance because of its universality in EIS disclosures, and because the Clean Water Act requires the Army Corps of Engineers, which permits wetland disturbance, to approve the least damaging practicable alternative. ${ }^{39} \mathrm{Com}-$ paring changes to surface disturbance against changes in wetland disturbance may therefore provide some insight into the comparative effect of NEPA and section 404 of the Clean Water Act.

We track job creation and tax revenue generation in order to assess the relationship between reductions in environmental impact and changes in economic benefits. We assume that wells will produce similar volumes of hydrocarbons, and that the number of wells can therefore also be used as an indicator of potential economic benefits. We track the number of well pads, miles of road, and miles of pipeline as indicators of surface impact because the maturation of directional drilling and hydraulic fracturing technologies may allow multiple

39. 40 C.F.R. $\$ 230.10$ (a) (2014). 
wells to be drilled from a single pad. This, in turn, could drive a reduction in surface disturbance. Comparing changes in the number of wells and well pads may provide some insight into whether impact reduction is driven by NEPA or other factors.

Air emissions were disclosed in almost all EISs, providing a suite of common impact reduction indicators. Some criteria pollutants, however, have a higher importance in the O\&G context. Based on modeling for the Greater Natural Buttes EIS, for example, emissions of particulate matter less than $10 \mu \mathrm{m}$ in diameter ("PM 10 ") would increase by $171 \%$ to $449 \%$ depending on the amount of development approved. ${ }^{40}$ Emission of nitrogen oxides ("NO"), by comparison, would increase by just $21 \%$ to $46 \% .{ }^{41}$ While the change in $\mathrm{PM}_{10}$ dramatically outpaces changes in $\mathrm{NO}_{x}$ emissions, $\mathrm{NO}_{\mathrm{x}}$ emissions are generally a higher concern for regulators. The Intermountain West has traditionally had very good air quality, and particulate levels are generally well below National Ambient Air Quality Standards ("NAAQS"). Mountain valleys experiencing $O \& G$ development, however, are frequently struggling with ozone (“ $\mathrm{O}_{3}$ ”) readings exceeding NAAQS. ${ }^{42}$ Minimizing tropospheric $\mathrm{O}_{3}$ formation necessitates reducing emissions of the chemicals that react with sunlight to form $\mathrm{O}_{3} \cdot \mathrm{NO}_{x}$ is an important $\mathrm{O}_{3}$ precursor and, therefore, represents the more important indicator, at least with respect to Clean Air Act ${ }^{43}$ compliance. ${ }^{44}$ Emission controls used to address $\mathrm{NO}_{\mathrm{x}}$ emissions may provide a secondary benefit by reducing emissions of other criteria pollutants.

\section{Theory}

Our first hypothesis, based on informal review of numerous NEPA documents, is that the proposed action is likely to undergo modification throughout the NEPA process, and that final approvals are likely to authorize a level of impact that is lower than initially proposed. We test this hypothesis by comparing predictions of quantifiable environmental indicators at multiple points during the NEPA process and quantifying how these indicators change over time.

Our second hypothesis, in light of criticisms of NEPA compliance's negative impact on project cost and feasibility, is that reductions in environmental impact will come at a heavy economic cost, as measured in changes to capital cost, employment, and tax revenue generation. We test this hypothesis by tracking changes to quantifiable economic indicators throughout the NEPA process and comparing those changes to changes in environmental impacts.

40. Bureau of Land Mgmt., U.S. Dep't of the Interior, Greater Natural Buttes Final Environmental Impact Statement, App. G at ES-3 (2012).

41. Id.

42. Peter M. Edwards et al., High Winter Ozone Pollution From Carbonyl Photosynthesis in an Oil and Gas Basin, 514 Nature 351, 351-54 (2014); Marco Rodriguez et al., Regional Impacts of Oil and Gas Development on Ozone Formation in the Western United States, 59 J. Air \& Waste Mgmt. Ass'N 1111, 1111-18 (2009).

43. Clean Air Act, Pub. L. No. 88-206, 77 Stat. 392 (1963) (codified as amended at 42 U.S.C. $\$ \$ 7401-7671 \mathrm{q}(2012))$.

44. Volatile organic compounds combine with $\mathrm{NO}_{\mathrm{x}}$ to form $\mathrm{O}_{3}$, but were not addressed because of inconsistent disclosure across $\mathrm{O} \& \mathrm{G}$ projects.
Our third hypothesis is that impact reductions will predominantly occur between the draft and final EIS. We test this hypothesis by comparing changes in environmental impact between draft and final EISs and the ROD.

Our fourth hypothesis, in light of NEPA's procedural mandate, is that other laws will drive the majority of impact reductions. We test this hypothesis by comparing environmental impact reductions for indicators that are subject to independent statutory or regulatory mandates to reduce emissions or impact to indicators that are subject to no such independent mandate.

Our fifth hypothesis is that EISs that consider more alternatives will result in greater environmental impact reduction. This hypothesis recognizes that alternatives are considered the "heart of the environmental impact statement" Congress intended "that consideration of alternatives, combined with mandatory findings regarding the environmental cost of each, would motivate agencies to take greater interest in less-harmful options." ${ }^{46}$ We test this hypothesis by dividing EISs into two groups, based on the number of alternatives considered, and comparing the amount of impact reduction that occurred for each group.

\section{Results}

\section{A. EIS Preparation Time}

Between 1998 and 2007, deWitt and deWitt (2008) reported that federal agencies took, on average, 1227 days to proceed from NOI to final EIS. ${ }^{47}$ While deWitt and deWitt (2008) did not provide completion time for BLM EISs, they did note that the U.S. Forest Service proceeded faster than its sister agencies, averaging 990 days from NOI to final EIS. ${ }^{48}$ Both figures include the time to complete a supplemental EIS where supplementation was required. As deWitt and deWitt (2013) reported subsequently, EIS preparation time increased by a rate of 19.9 days annually from 2007 through 2010, and BLM's "non-planning" EISs required an average of 1421 days to proceed from NOI to final EIS, though this does not appear to reflect time required to complete required supplemental EISs, if any. ${ }^{49}$

We found that preparation of O\&G EISs can take longer than other EISs. The time taken to complete an O\&G EIS, as measured from the NOI to final EIS, averages 1553.1 days (range $=980$ to 2313 days), or 1617.9 days (range $=1057$ to 2556 days) when measured from NOI to the ROD. We also found that it takes longer to prepare a draft EIS (an average of 990.5 days, measured as the time between NOI and draft

45. 40 C.F.R. $\$ 1502.14$ (2014).

46. James Allen, NEPA Alternatives Analysis: The Evolving Exclusion of Remote and Speculative Alternatives, 25 J. Land Res. \& EnvTl. L. 287, 292 (2005) (citing 115 Cong. Rec. 40,416 (1969) (statement of Senator Jackson accompanying NEPA's conference committee report)).

47. deWitt \& deWitt, How Long Does It Take?, supra note 22, at 168.

48. Id.

49. deWitt \& deWitt, Preparation Times, supra note 22 , at 128 . deWitt $\&$ deWitt describe "non-planning" EISs as those completed for purposes other than general resource management plans or national and regional planning. See id. 
Table 2

Change During the EIS Process

\begin{tabular}{|c|c|c|c|c|}
\hline $\begin{array}{c}\text { Impact } \\
\text { (Sample Size) }\end{array}$ & $\begin{array}{c}\text { Initial Value, } \\
\text { Final Value } \\
\text { (\% Reduction of Initial Value) }\end{array}$ & $\begin{array}{c}\text { Change Draft to Final } \\
\text { EIS } \\
\text { (\% of Total Change) }\end{array}$ & $\begin{array}{l}\text { Change Final EIS to } \\
\text { ROD } \\
\text { (\% of Total Change) }\end{array}$ & $\begin{array}{l}\text { Total } \\
\text { Change }\end{array}$ \\
\hline $\begin{array}{l}\text { Permanent Surface Disturbance } \\
\text { (acres) } \\
(n=13)\end{array}$ & $\begin{array}{r}6,137.7 \\
5,348.8 \\
(13 \%)\end{array}$ & $\begin{array}{r}-696.7^{* *} \\
(88 \%)\end{array}$ & $\begin{array}{l}-92.3 \\
(12 \%)\end{array}$ & $-788.9 * *$ \\
\hline $\begin{array}{l}\text { Temporary Surface Disturbance } \\
(\text { acres) } \\
(n=13)\end{array}$ & $\begin{array}{r}10,846.5 \\
9,784.2 \\
(10 \%)\end{array}$ & $\begin{array}{r}-912.9 * * \\
(86 \%)\end{array}$ & $\begin{array}{l}-149.4 \\
(14 \%)\end{array}$ & $-1,062.3^{* *}$ \\
\hline $\begin{array}{l}\text { Wetland Disturbance (acres) } \\
(n=8)\end{array}$ & $\begin{array}{r}139.8 \\
98.8 \\
(30 \%) \\
\end{array}$ & $\begin{array}{r}-41.0 \\
(100 \%) \\
\end{array}$ & $\begin{array}{r}0 \\
(0 \%) \\
\end{array}$ & -41.0 \\
\hline $\begin{array}{l}\text { Well Pads } \\
(n=13)\end{array}$ & $\begin{array}{r}3,221.5 \\
2,967.1 \\
(8 \%)\end{array}$ & $\begin{array}{l}-219 * \\
(86 \%)\end{array}$ & $\begin{array}{l}-35.5 \\
(14 \%)\end{array}$ & $-254.5 * *$ \\
\hline $\begin{array}{l}\text { Wells } \\
(n=13)\end{array}$ & $\begin{array}{r}3,652.4 \\
3,618.8 \\
(<1 \%)\end{array}$ & $\begin{array}{r}-22.4 \\
(67 \%)\end{array}$ & $\begin{array}{r}-11.2 \\
(33 \%)\end{array}$ & $-33.5^{*}$ \\
\hline $\begin{array}{l}\text { Roads (miles) } \\
(n=13)\end{array}$ & $\begin{array}{r}845.6 \\
811.7 \\
(4 \%)\end{array}$ & $\begin{array}{l}-24.4^{*} \\
(72 \%)\end{array}$ & $\begin{array}{r}-9.5 \\
(28 \%)\end{array}$ & $-33.9 * *$ \\
\hline $\begin{array}{l}\text { Pipelines (miles) } \\
(n=/ 2)\end{array}$ & $\begin{array}{r}2,150.4 \\
2,102.1 \\
(2 \%)\end{array}$ & $\begin{array}{r}-33.6 \\
(70 \%) \\
\end{array}$ & $\begin{array}{r}-14.7 \\
(30 \%) \\
\end{array}$ & $-48.3^{*}$ \\
\hline $\begin{array}{l}\text { Water Use (acre-feet) } \\
(n=/ 2)\end{array}$ & $\begin{array}{r}15,182.8 \\
14,353.8 \\
(5 \%)\end{array}$ & $\begin{array}{l}-471.3 \\
(57 \%)\end{array}$ & $\begin{array}{l}-357.6 \\
(43 \%)\end{array}$ & -826.9 \\
\hline $\begin{array}{l}\mathrm{NO}_{x} \text { (tons per year) } \\
(n=13)\end{array}$ & $\begin{array}{r}2,487.5 \\
1,890.2 \\
(24 \%)\end{array}$ & $\begin{array}{r}-505.5 * \\
(85 \%)\end{array}$ & $\begin{array}{r}-91.8 \\
(15 \%)\end{array}$ & $-597.3^{* *}$ \\
\hline $\begin{array}{l}\mathrm{SO}_{2} \text { (tons per year) } \\
(n=12)\end{array}$ & $\begin{array}{l}53.1 \\
50.3 \\
(5 \%)\end{array}$ & $\begin{array}{r}-1.9 \\
(68 \%)\end{array}$ & $\begin{array}{r}-0.9 \\
(32 \%)\end{array}$ & -2.8 \\
\hline $\begin{array}{l}\text { CO (tons per year) } \\
(n=10)\end{array}$ & $\begin{array}{r}1,714.7 \\
1,623.7 \\
(5 \%)\end{array}$ & $\begin{array}{r}-33.0 \\
(36 \%)\end{array}$ & $\begin{array}{r}-58.0 \\
(64 \%)\end{array}$ & -91.0 \\
\hline $\begin{array}{l}\mathrm{PM}_{2.5} \text { (tons per year) } \\
(n=I I)\end{array}$ & $\begin{array}{l}344.0 \\
260.6 \\
(24 \%)\end{array}$ & $\begin{array}{r}-79.1 \\
(95 \%)\end{array}$ & $\begin{array}{l}-4.3 \\
(5 \%)\end{array}$ & $-83.4^{*}$ \\
\hline $\begin{array}{l}\mathrm{PM}_{10} \text { (tons per year) } \\
(n=12)\end{array}$ & $\begin{array}{r}1,795.8 \\
1,380.9 \\
(23 \%)\end{array}$ & $\begin{array}{r}-399.6 * \\
(96 \%)\end{array}$ & $\begin{array}{l}-15.3 \\
(4 \%)\end{array}$ & $-414.9 *$ \\
\hline $\begin{array}{l}\text { State and Local Tax (dollars per } \\
\text { year) } \\
(n=9)\end{array}$ & $\begin{array}{r}11,703,556 \\
I I, 039,111 \\
(6 \%)\end{array}$ & $\begin{array}{r}-622,220 \\
(94 \%)\end{array}$ & $\begin{array}{r}-42,222 \\
(6 \%)\end{array}$ & $-664,440$ \\
\hline $\begin{array}{l}\text { Jobs } \\
(n=12)\end{array}$ & $\begin{array}{r}667.8 \\
648.8 \\
(3 \%)\end{array}$ & $\begin{array}{r}-17.8 \\
(93 \%)\end{array}$ & $\begin{array}{r}-1.3 \\
(7 \%)\end{array}$ & $-19.1 *$ \\
\hline
\end{tabular}


EIS), than to go from a draft EIS to the ROD (627.4 days on average).

\section{B. NEPA Process and Impact Reduction}

Consistent reductions in environmental and economic measures occur as projects progress from the draft EIS to the final EIS and then to the ROD. The majority of reductions occurred between the draft EIS and the final EIS, with relatively minor reductions occurring between the final EIS and ROD. A summary of results is shown in Table 2.

\section{Alternatives Considered}

The number of alternatives considered during the draft EIS and final EIS ranged from two to ten and two to eight respectively. The mean number of alternatives considered during the draft EIS was 4.6 and the final EIS was 4.3. The difference in means between draft EISs and final EISs can be attributed to one project. The draft EIS for the Jonah Infill Project considered ten alternatives, but five of these alternatives were not carried forward into the final EIS because the BLM concluded that they were duplicative of the remaining alternatives. $^{50}$

\section{Relationship Between Alternatives Considered and Proposed Project Impacts}

Of the impact factors, acres of proposed temporary surface disturbance was the best predictor of the number of alternatives considered $(r(12)=0.51, p=0.0058)$. This factor was followed by the proposed number of wells $(r(12)=0.49$, $p=0.0073)$, proposed acres of permanent surface disturbance $(r(12)=0.48, p=0.0082)$, and proposed number of well pads $(r(12)=0.47, p=0.0098)$. In contrast, the number of alternatives was not a statistically significant predictor of the amount of reduction for any of the impact measures.

\section{E. Alternatives and Impact Reduction}

To better assess the relationship between the number of alternatives and impact reduction, we separated the EISs into two groups based on the number of alternatives considered in the final EIS ${ }^{51}$ : (1) those that considered four or more alternatives ("More Alternatives Group") and (2) those that considered three or fewer alternatives ("Fewer Alternatives Group"). This resulted in four EISs in the Fewer Alternatives Group and nine EISs in the More Alternatives Group.

The More Alternatives Group had greater impact reductions than the Fewer Alternative Group for eleven of the

50. Bureau of Land Mgmt., U.S. Dep't of the Interior, Final Environmental Impact Statement: Jonah Infill Drilling Project Sublette County, Wyoming 2-7 to 2-8 (2006).

51. We use the number of alternatives considered in the final EIS because the mean number of alternatives considered decreased from the draft EIS to the final EIS in our sample. Consequently, the alternatives considered at the final EIS stage are a better representation of the options available to the agency decisionmaker when making the final agency decision at the ROD stage. thirteen environmental impacts. Six of these differences were statistically significant. The Fewer Alternatives Group had lower impact reductions for the two economic metrics; however, neither of these differences was statistically significant. We also calculated the percent reduction for each impact by group, which was accomplished by dividing the impact reduction for each value by the initial value of the impact. We include this value for descriptive purposes, as there is an apparent relationship between initial impact levels and the number of alternatives considered. A summary of these results is shown in Table 3 .

EISs that considered fewer alternatives were completed on average 312.1 days sooner than those that considered more alternatives. EISs that considered fewer alternatives took a mean of 1408.5 days to complete. EISs that considered more alternatives took a mean of 1720.6 days.

\section{Discussion}

\section{A. EIS Preparation Time}

Based on our analysis and data from deWitt and deWitt (2008 \& 2013), it appears that O\&G EISs take longer to prepare than EISs for other types of projects. While this analysis does not indicate why O\&G EISs take longer, we posit that the size, complexity, and public attention associated with these projects drives longer completion times. Agency staffing levels may also play an important role in increasing preparation time.

In our study, one of thirteen EISs (7.7\%) required supplementation between issuance of the draft EIS and the ROD. This result is consistent with deWitt and deWitt's (2008) finding that $6.2 \%$ of EISs required pre-ROD supplementation. ${ }^{52}$ The deWitt and deWitt (2008) report also found that publication of a supplemental EIS added an average of 835 days to the time required for NEPA compliance. ${ }^{53}$

With O\&G EISs taking an average of over 4.4 years to proceed from NOI to ROD, frustration at the time and expense involved in NEPA compliance is not surprising. While legislative proposals to establish deadlines for EIS completion appear responsive to these concerns, they could produce the opposite result. If an accelerated timeline results in NEPA documentation that fails to satisfy the "hard look" requirement, supplementation will be required, and the expense and time involved in completing a supplement-almost 2.3 additional years according to deWitt and deWitt's (2008) analysis ${ }^{54}$-may outweigh the benefit resulting from expedited NEPA. Increased emphasis on NEPA's mandate to "deemphasize insignificant issues" $" 55$ may have a more lasting impact, as may collaborative approaches to NEPA that reduce the likelihood of litigation-driven EIS supplementation.

52. deWitt \& deWitt, How Long Does It Take?, supra note 22, at 171.

53. Id. at 170 .

54. Id. at 169-70.

55. 40 C.F.R. $\$ 1500.4(f),(g)(2014)$. 
Table 3

Impact Reduction and Number of Alternatives

\begin{tabular}{|c|c|c|c|}
\hline Impacts & $\begin{array}{c}\text { Fewer Alternatives Group } \\
\text { Impact Reduction } \\
\text { (\% Reduction of Initial Value) }\end{array}$ & $\begin{array}{c}\text { More Alternatives Group } \\
\text { Impact Reduction } \\
\text { (\% Reduction of Initial Value) }\end{array}$ & $\begin{array}{c}\text { Difference in Impact } \\
\text { Reduction Between } \\
\text { Two Groups }\end{array}$ \\
\hline $\begin{array}{l}\text { Permanent Surface Disturbance } \\
\text { (acres) }\end{array}$ & \begin{tabular}{|r|}
81.4 \\
$(3 \%)$ \\
\end{tabular} & $\begin{array}{r}, 103.4 \\
(15 \%) \\
\end{array}$ & $1,022.0 * *$ \\
\hline $\begin{array}{l}\text { Temporary Surface Disturbance } \\
\text { (acres) }\end{array}$ & $\begin{array}{r}81.4 \\
(2 \%)\end{array}$ & $\begin{array}{r}1,492.2 \\
(11 \%)\end{array}$ & $1,416.8 * *$ \\
\hline Wetland Disturbance (acres) & $\begin{array}{r}52.5 \\
(57 \%)\end{array}$ & $\begin{array}{r}37.2 \\
(24 \%)\end{array}$ & -15.3 \\
\hline Well Pads & $\begin{array}{r}36 \\
(5 \%)\end{array}$ & $\begin{array}{l}351.6 \\
(8 \%)\end{array}$ & $315.6 *$ \\
\hline Wells & $\begin{array}{r}3.8 \\
(<1 \%)\end{array}$ & $\begin{array}{r}46.8 \\
(<1 \%)\end{array}$ & 43.0 \\
\hline Roads (miles) & $\begin{array}{r}2.9 \\
(1 \%)\end{array}$ & $\begin{array}{r}47.7 \\
(4 \%)\end{array}$ & $44.8^{*}$ \\
\hline Pipelines (miles) & $\begin{array}{r}13.9 \\
(6 \%)\end{array}$ & $\begin{array}{r}59.8 \\
(2 \%)\end{array}$ & 45.7 \\
\hline Water Use (acre-feet) & $\begin{aligned} 2,231 \\
(6 \%)\end{aligned}$ & $\begin{array}{l}129.8 \\
(3 \%)\end{array}$ & $-2,101.1$ \\
\hline $\mathrm{NO}_{\times}$(tons per year) & $\begin{array}{l}184.8 \\
(10 \%)\end{array}$ & $\begin{array}{l}780.7 \\
(28 \%)\end{array}$ & 595.9 \\
\hline $\mathrm{SO}_{2}$ (tons per year) & $\begin{array}{r}1.5 \\
(8 \%)\end{array}$ & $\begin{array}{r}3.6 \\
(5 \%)\end{array}$ & 2.1 \\
\hline $\mathrm{CO}$ (tons per year) & $\begin{array}{l}38.0 \\
(6 \%)\end{array}$ & $\begin{array}{r}126.3 \\
(5 \%)\end{array}$ & 88.3 \\
\hline $\mathrm{PM}_{2.5}$ (tons per year) & $\begin{array}{r}0.0 \\
(0 \%)\end{array}$ & $\begin{array}{r}114.6 \\
(26 \%)\end{array}$ & $114.6 *$ \\
\hline $\mathrm{PM}_{10}$ (tons per year) & $\begin{array}{l}10.3 \\
(2 \%) \\
\end{array}$ & $\begin{array}{r}617.3 \\
(25 \%)\end{array}$ & $607.0 *$ \\
\hline $\begin{array}{l}\text { State and Local Tax (dollars per } \\
\text { year) }\end{array}$ & $\begin{array}{r}193,333 \\
(4 \%)\end{array}$ & $\begin{array}{r}900,000 \\
(6 \%)\end{array}$ & 706,700 \\
\hline Jobs & $\begin{array}{r}6.3 \\
(4 \%) \\
\end{array}$ & $\begin{array}{l}25.5 \\
(3 \%) \\
\end{array}$ & 19.2 \\
\hline
\end{tabular}

\section{B. Environmental Impact Reduction}

EISs appear to reduce environmental impacts. Impacts to all measured elements evidenced a reduction in impacts between draft EIS and ROD. On a percentage basis, reductions were largest for the air quality parameters $\mathrm{PM}_{10}, \mathrm{PM}_{2.5}$, and $\mathrm{NO}_{x}$, which all saw initial impacts reduced by $23 \%$ or more between draft EIS and ROD. Reductions in $\mathrm{PM}_{10}$ are important because $\mathrm{O} \& \mathrm{G}$ development is anticipated to result in a major increase in emission of these larger particulates. ${ }^{56}$ Reductions in $\mathrm{NO}_{x}$ are important because $\mathrm{NO}_{x}$ are chemical precursors of $\mathrm{O}_{3}$, and some valleys in Utah and Wyoming are experiencing very high $\mathrm{O}_{3}$ levels that have been attributed to O\&G development. ${ }^{57}$ Impacts to wetlands were also reduced by more than 30\% between draft EIS and ROD. Each of these elements is subject to independent action-forcing regulation, perhaps indicating that impact reductions are

56. Bureau of Land Mgmt., supra note 40.

57. Edwards et al., supra note 42; Rodriguez et al., supra note 42. attributable to compliance with environmental laws other than NEPA.

Sulfur dioxide ("SO $\mathrm{SO}_{2}$ ) and carbon monoxide ("CO") are also subject to independent action-forcing regulation, but both experienced statistically insignificant and comparatively minor impact reductions (initial impacts reduced by 5\%). Regulation alone, therefore, does not appear to guarantee significant impact reduction. Lower rates of emission reduction may indicate that less effort is expended on reducing emission of these pollutants because the project areas analyzed in these EISs appear to have ambient $\mathrm{SO}_{2}$ and $\mathrm{CO}$ levels that are well below NAAQS. ${ }^{58}$ Other potential alternate explanations are discussed below. ${ }^{59}$

A reduction of less than $1 \%$ in the number of wells drilled resulted in 13\% reductions in permanent surface disturbance and $10 \%$ reductions in temporary surface disturbance. Both

58. Bureau of Land Mgmt., supra note 40, at 2-3, 2-4, 2-7 (discussing background concentrations air quality standards).

59. See infra Part V.D. 
reductions were statistically significant, indicating meaningful reductions may occur without a hard regulatory mandate such as the Clean Air Act or Clean Water Act. These impact reductions are consistent with arguments that NEPA is effective in its goal of encouraging agencies to take a hard look at feasible alternatives to the proposed action and that reductions in impact can be achieved at a comparatively small economic cost.

We anticipated that the concurrent maturation of directional drilling and hydraulic fracturing techniques would result in a reduction in surface disturbance. In contrast to vertical wells which tap only the hydrocarbons directly below the well, directional drilling allows operators to drill non-vertical wells that more efficiently drain hydrocarbons located in narrow horizontal formations that may be thousands of feet from the well pad. ${ }^{60}$ Hydraulic fracturing injects liquids into hydrocarbon bearing formations in order to increase formation permeability and the rate of hydrocarbon recovery. ${ }^{61}$ The co-utilization of these technologies would allow developers to locate multiple wells from a single well pad, and in so doing, reduce the total number of well pads developed. The reduction in well pads would equate to a reduction in surface disturbance. ${ }^{62}$ The number of well pads did decrease by $8 \%$ between draft EIS and ROD, compared to a less than $1 \%$ reduction in the number of wells over that same period, which is consistent with a shift towards development of multiple wells from a single pad. The reduction in number of well pads also likely contributed to the reduction in road and pipeline construction and associated disturbance, because fewer pads necessitate a less extensive inter-pad road and utility network. ${ }^{63}$

\section{Impacts on Economic Benefits}

As hypothesized, environmental impact reduction appears to come at an economic cost, though that cost is lower than we anticipated. Both job creation and state and local tax revenue declined between the draft EIS and ROD; however, declines in impacts to key environmental indicators occurred at higher rates than declines in economic indicators. Projected job growth declined by a statistically significant 3\% between the draft EIS and the ROD. However, declines in job growth occurred at a lower rate than reductions in eleven of thirteen environmental impacts, nine of which experienced statistically significant reductions. While reductions in state and local tax revenue generation declined by $6 \%$ between draft EIS and ROD, a lower rate than seven of thirteen environ-

60. See Bureau of Land Mgmt., U.S. Dep't of the Interior, Northern San Juan Basin Coal Bed Methane Final Environmental Impact Statement 2-4 (2006) (discussing alternate drilling technologies); see also Oil Field Glossary, Schlumerger, http://www.glossary.oilfield.slb.com/ (last visited Sept. 28, 2015).

61. Cong. Research Serv., R40894, Unconventional Gas Shales: Development, Technology, and Policy Issues 21-25 (2009); see Oil Field Glossary, supra note 60

62. Dan Arthur \& David Cornue, Technologies Reduce Pad Size, Waste, Am. Oil \& Gas Rep., Aug. 2010; see Bureau of Land Mgmt., supra note 40 at 2-32 (showing reduced surface disturbance under alternative utilizing directional 63. Id. mental indicators, declines in tax revenue were not statistically significant.

With four environmental indicators experiencing more than $20 \%$ reductions in impacts and nine environmental indicators experiencing statistically significant reductions, it appears that environmental impacts can be reduced through the NEPA process without driving a commensurate reduction in economic benefits. Furthermore, reductions in pollution emissions may provide an indirect economic benefit by reducing absenteeism and health care costs. ${ }^{64}$ Also absent from our analysis of economic impacts are the potential benefits to recreational use of public lands that result from reduced well pad density.

\section{Impact Reduction and Causation}

Researchers speculate that the NEPA process itself can drive impact reduction through several mechanisms. For example, NEPA forces a scientific analysis of a proposed action, and this analysis alone could indirectly lead to impact reduction. ${ }^{65}$ The "internal reform" model suggests that NEPA forces changes in agency priorities, personnel, and process that result in more sustainable decision-making. ${ }^{66}$ In contrast, the "external reform" model contends that the increased transparency and public involvement associated with NEPA may result in more sustainable decision-making. ${ }^{67}$ The internal and external models may work together to provide synergistic benefits.

Our results indicate that a statistically significant reduction in project impacts occurs over the course of the NEPA process, and the largest reduction- $-80 \%$ of total impact reduction across all elements-occurs between publication of the draft EIS and final EIS. The reduction in impacts could be attributed to NEPA-related mechanisms, intervening variables, or a combination of both. Possible intervening

64. See, e.g., National Ambient Air Quality Standards for Particulate Matter, 78 Fed. Reg. 3086, 3089 (proposed Jan. 15, 2013) (to be codified at 40 C.F.R. $\$ 50.18$ ) (estimating the economic benefit derived from revised $\mathrm{PM}_{2.5}$ standards at $\$ 3.6$ to $\$ 9.1$ million).

65. Cashmore et al., supra note 10, at 304-05.

66. Robert V. Bartlett, The Rationality and Logic of NEPA Revisited, in ENVIRONmental Policy and NEPA 55-56 (Ray Clark \& Larry Canter eds., 1997). Prior to NEPA's enactment, agencies were professionally homogeneous; for example, the U.S. Forest Service was predominantly staffed by foresters and the U.S. Bureau of Reclamation with engineers. This homogeneity resulted in agencies that were less sensitive to environmental impacts outside of their realm of expertise. After NEPA was enacted, agencies were forced to "diversify their staffs so that specialists could take responsibility for preparing EISs. . .." Paul J. Culhane, NEPA's Impacts on Federal Agencies, Anticipated and Unanticipated, 20 EnVTL. L. 681, 691 (1990). The most obvious example, described by Friesema and Culhane, is the U.S. Forest Service using "subtle and not so subtle techniques" to generate enough public pressure to justify severe restrictions and project modifications during the NEPA process. H. Paul Friesema \& Paul J. Culhane, Social Impacts, Politics, and the Environmental Impact Statement Process, 16 Nat. Res. J. 339, 354-55 (1976).

67. Bartlett, supra note 66; see Culhane, supra note 66, at 692 ("[NEPA provided] a new opportunity for environmental groups, concerned citizens, and individual scientists to influence agency decisions. Before NEPA, these groups were, at best, underrepresented in agencies' constituency networks.") (concluding that NEPA encourages an agency to consider ramifications of a decision on "[their] public reputation and political capital; costly and time-consuming lawsuits; disciplining congressional responses including budget reductions, legislative amendments, or oversight hearings; and disciplining personnel, policy, or budget moves by the White House"). 
causes include: (1) impact reduction occurring during earlier NEPA decisions, (2) gaming of the NEPA process, (3) legal requirements contained in other environmental laws, and (4) intervening economic or technological factors. These are addressed in turn.

\section{Impact Reduction During Antecedent NEPA}

O\&G development occurring on federal land necessitates a series of federal decisions preceding the O\&G EIS, each of which may trigger NEPA and provide an opportunity for impact reduction. ${ }^{68}$ Because this Article addresses only the final phase of a multi-tiered federal decision-making process, it may understate total impact reductions.

O\&G leasing and development decisions occur against the backdrop of decisions contained in the BLM's Resource Management Plans ("RMPs"). ${ }^{69}$ RMPs contain broad-scale decisions, such as which areas will be open or closed to mineral development, and cover a planning area that can be several million acres in size. RMPs are invariably major federal actions with significant environmental impact and, therefore, require EIS preparation, which subjects them to the kinds of iterative impact reductions already discussed. ${ }^{70}$ For areas that are open to development, RMPs typically indicate which surface use stipulations will apply. ${ }^{71}$

The surface use stipulations contained in RMPs fall into four general categories. Standard lease terms and conditions allow the BLM to require operators to move surface disturbing activity by up to 200 meters or limit activity by up to 60 days. ${ }^{72}$ The BLM can impose longer timing limits or broader surface use restrictions, under "timing limits" or "conditional surface use" stipulations, as needed to protect sensitive resources. ${ }^{73}$ Where timing limits and conditional surface use stipulations are insufficient, the BLM can impose a "no surface use" stipulation, which precludes surface disturbing activities while allowing operators to access hydrocarbons from horizontal wells drilled outside the no surface occupancy area. ${ }^{74}$ The BLM can also choose to forego leasing entirely. ${ }^{75}$ Surface use stipulations contained in RMPs provide the BLM with a powerful tool to protect sensitive resources, and significant environmental impacts may thus be avoided before the O\&G development EIS is even considered.

Our analysis looks only at environmental impact reduction occurring after the BLM determines which lands will be open to leasing and, for those lands, which surface use stipulations will apply. Accordingly, our analysis almost certainly under-reports total impact reduction occurring through all phases of the NEPA process. Research investigating impact reduction occurring as part of the antecedent NEPA analysis for RMP decisions is underway and will provide additional

68. See Bureau of Land Mgmt., U.S. Dept. of the Interior, H-1601-1, Land Use Planning Handbook 11-13 (2005).

69. Land use plans are required under 43 U.S.C. $\$ 1712$ (a) (2012).

70. See Bureau of Land Mgmt., supra note 68, at 17, app. C at 23-24.

71. See id. at 13 .

72. 43 C.F.R. $\$ 3101.1-2(2014)$

73. See Bureau of Land Mgmt., supra note 68, app. C at 23-24.

74. See id.

75. See id. insight into the longitudinal relationship between these tiered NEPA decisions. ${ }^{76}$

\section{Reductions Driven by Other Environmental Laws}

The legal test of a NEPA document is not whether it produces the least environmentally damaging alternative, but whether the lead agency took a "hard look" at the impacts of the proposed action and a reasonable range of alternatives to that action. ${ }^{77}$ In contrast, laws like the Clean Air Act, Clean Water Act, and Endangered Species Act require impact avoidance and minimization as well as mitigation of unavoidable environmental impacts. The Clean Air Act, for example, requires employment of the "best available control technology" for new major emitting facilities. ${ }^{78}$ The Clean Water Act's section 404(b)(1) guidelines require that "no discharge of dredged or fill material shall be permitted if there is a practicable alternative to the proposed discharge which would have less adverse impact on the aquatic ecosystem." ${ }^{79}$ Similarly, section 7(a)(2) of the Endangered Species Act imposes a duty on federal agencies to avoid jeopardizing the continued existence of listed species and to avoid adverse modification of designated critical habitat. ${ }^{80}$ It follows that, while NEPA may require a public vetting of the environmental consequences of various courses of action, other laws could drive impact reduction.

If NEPA's critics are correct, and NEPA does significantly less to advance environmental protection, we would anticipate that the impact reductions to environmental attributes that are subject to independent action-forcing regulations, such as air quality standards, restrictions on dredging or filling wetlands, or endangered species protections, would far outpace the reductions to environmental attributes that are uniquely attributable to NEPA. While impact reductions for some regulated resources did occur at very high rates when compared to unregulated resources, reductions in temporary and permanent surface disturbance were statistically significant and cannot be attributed directly to a regulatory mandate to minimize these impacts. ${ }^{81}$ These findings may indicate that NEPA can lead to environmental impact reductions independent of other environmental laws.

Reductions in air quality impacts, however, are an area where reduction appears to be driven heavily by other environmental laws. Elevated ground-level $\mathrm{O}_{3}$ levels have been discovered in many rural counties that are experiencing

76. John Ruple \& Mark Capone, NEPA, FLPMA, and Impact Reduction: An Empirical Assessment of BLM Resource Management Planning in the Intermountain West (2015) (unpublished manuscript) (on file with Authors).

77. Balt. Gas \& Elec. Co. v. Nat. Res. Def. Council, 462 U.S. 87, 97 (1983); Kleppe v. Sierra Club, 427 U.S. 390, 410 n.21 (1976).

78. 42 U.S.C. $\$ 7475(\mathrm{a})(4)(2012)$

79. 40 C.F.R. $\$ 230.10$ (a) (2014).

80. 16 U.S.C. $\$ 1536(a)(2)(2012)$.

81. Although not quantified in this study, the Endangered Species Act and consultations with the U.S. Fish and Wildlife Service appeared to play a relatively minor role in surface disturbance reduction. We speculate that this minor role in O\&G EISs is, in large part, due to (1) habitat avoidance measures called for in the RMP, and (2) the avoidance of riparian habitat impacts associated with Clean Water Act requirements. 
rapid O\&G development, ${ }^{82}$ raising concern that these areas may be designated as non-attainment areas for $\mathrm{O}_{3}$ under the Clean Air Act. ${ }^{83}$ Accordingly, increased emphasis has been placed on reducing emissions of $\mathrm{O}_{3}$ 's chemical precursors, such as volatile organic compounds ${ }^{84}$ and $\mathrm{NO}_{\times}{ }^{85}$ Such an emphasis is consistent with our finding that $\mathrm{NO}_{x}$ emission reductions were greater than reductions in other criteria pollutants assessed in O\&G EISs, with the exception of PM ${ }_{25}$. Accordingly, the Clean Air Act, rather than NEPA, may be the primary driver in $\mathrm{NO}_{x}$ emission reductions. Technologies deployed to reduce $\mathrm{NO}_{\mathrm{x}}^{\mathrm{x}}$ and volatile organic compound emissions may also provide some reduction in particulate emissions, ${ }^{86}$ potentially offering partial explanation for $\mathrm{PM}_{10}$ and $\mathrm{PM}_{2.5}$ emission reductions. As $\mathrm{SO}_{2}$ is not an $\mathrm{O}_{3}$ precursor, and $\mathrm{SO}_{2}$ levels are a less significant concern in most areas undergoing O\&G development, ${ }^{87}$ the absence of significant reductions in $\mathrm{SO}_{2}$ emissions is also consistent with this interpretation. However, even if the Clean Air Act is the primary driver behind emission reductions, NEPA may still play an important role in assessing the viability of specific pollution reduction technologies and thereby facilitate their deployment.

It therefore appears that NEPA can lead to a statistically significant reduction in some environmental impacts, even if reductions are not as rapid as those resulting from statutes that include a strong impact avoidance or minimization mandate. We hypothesize that NEPA's disclosure and hard look requirements focus agency and public attention towards impact reduction, even where hard regulatory triggers do not exist.

\section{Gaming NEPA}

When negotiating, parties often begin by asking for more than they expect to obtain in order to create room for concessions. ${ }^{88}$ Similarly, strategic NEPA proposal enlargement may occur if permittees believe the NEPA process will inevitably result in a reduction in the extent of authorized impacts or facilities. Proponents could inflate the initial proposal in order to obtain their desired outcome, following anticipated

82. Samuel Oltsman et al., Anatomy of Wintertime Ozone Associated With Oil and Natural Gas Extraction Activity in Wyoming and Utah, 2 Elem. ScI. ANTh. 1, 13 (2014).

83. See Miss. Comm'n on Env't Quality v. EPA, No. 12-1309, slip op. at 3, 23 (D.C. Cir. June 2, 2015) (involving numerous consolidated cases challenging EPA designation of the Uinta Basin as "unclassifiable" for ozone).

84. Volatile organic compound emissions were not reported consistently in the EISs we reviewed.

85. Ground-Level Ozone: Basic Information, U.S. Envtl. Protection Agency, http://www3.epa.gov/airquality/ozonepollution/resources.html (last visited Jan. 20, 2015); see also Edwards et al., supra note 42, at 351-55; Rodriguez et al., supra note 42.

86. See, e.g., Michael J. Kleemana et al., Control Strategies for the Reduction of Airborne Particulate Nitrate in California's San Joaquin Valley, 39 AтмоspHeric Env'T 5325, 5325-41 (2005) (noting that each gram of $\mathrm{NO}_{x}$ emitted locally within the San Joaquine Valley produced $0.23-0.31$ grams of particulate ammonium nitrate).

87. See, e.g., Bureau of Land MGmt, supra note 40, at 2-3, 2-4, 2-7 (showing $\mathrm{SO}_{2}$ levels are well below NAAQS).

88. See Gary Goodpaster, A Primer on Competitive Bargaining, 1996 J. Dis. Res. 325, 351, 355 (1996); Richard Birke \& Craig R. Fox, Psychological Principles in Negotiating Civil Settlements, 4 Harv. Negot. L. Rev. 1, 41 (1999). reductions. Alternatively, permittees may inflate the initial proposal so they may later offer to reduce impacts and, by doing so, curry favor with the lead agency and the public.

While gaming during the NEPA process has been suggested, ${ }^{89}$ there is little empirical information to indicate whether gaming is a common practice. In contrast, gaming by exaggeration or inflation of cost estimates is a documented industry strategy in Clean Water Act and Clean Air Act regulation. ${ }^{90}$ The result of gaming in these contexts is "illusory" impact reductions. ${ }^{91}$ If gaming of the NEPA process does occur, some amount of the impact reduction we measured may be illusory.

\section{Intervening Economic or Technological Factors}

Technology and associated economic factors may change over time, making environmentally preferable technologies easier to deploy commercially. For example, the maturation and convergence of directional drilling and hydraulic fracturing technologies occurred concurrent with the proposals evaluated in our analysis. ${ }^{92}$ Dramatic increases in O\&G production are widely attributed to this technological maturation and convergence..$^{3}$ Hydraulic fracturing allows operators to greatly increase production, while improvements in directional drilling technology allow O\&G operators to reach laterally for much greater distances. ${ }^{94}$ This technological convergence allows operators to drill multiple wells from a single well pad, thereby allowing higher levels of O\&G production from fewer well pads..$^{95}$ Our results indicate that consolidating wells onto fewer well pads reduced the amount of surface disturbance associated with well pads and also the amount of roads and pipelines needed to connect these pads

89. See Robert W. Adler, In Defense of NEPA: The Case of the Legacy Parkway, $26 \mathrm{~J}$. Land Res. \& Envtl. L. 297, 300 (2006).

90. Ann Powers, Reducing Nitrogen Pollution on Long Island Sound: Is There A Place for Pollutant Trading?, 23 Colum. J. ENvTL. L. 137, 158 (1998) ("[I]t is obvious that some of the disparity between estimates and current costs stems from inflated estimates used by industry to oppose the program."); Richard Toshiyuki Drury et al., Pollution Trading and Environmental Injustice: Los Angeles' Failed Experiment in Air Quality Policy, 9 Duke Envtl. L. \& Pol'y F. 231, 259 (1999) ("Pollution trading programs create stronger incentives to manipulate the numbers and cheat, because credits that are fraudulently created are still worth money."); Robert V. Percival, Regulatory Evolution and the Future of Environmental Policy, 1997 U. Chi. LegaL F. 159, 180 (1997) ("[I]t is in the strategic interest of regulatory targets to exaggerate prospective costs in an effort to avoid regulation.").

91. Drury et al., supra note 90, 263-64 (1999). On the other side, NEPA cynics claim that agencies have learned to game the NEPA process so that results are typically decided at the outset, and simply ratified by a well-oiled EIS factory in which the right issues are addressed, and the right words are magically invoked to survive any judicial review. See Adler, supra note 89.

92. See Cong. Research Serv., supra note 61 at 17-18 (explaining that "[c]ombining hydraulic fracturing with directional drilling has opened up production of tighter (less permeable) petroleum and natural gas reservoirs, and in particular, unconventional gas shales").

93. Timothy Fitzgerald, Frackonomics: Some Economics of Hydraulic Fracturing, 63 Case W. Res. L. Rev. 1337, 1344 (2013).

94. Michael J. Wozniak \& Jamie L. Jost, Horizontal Drilling: Why Its Much Better to "Lay Down" Than to "Stand Up" and What Is an "18० Azimuth" Anyway?, 57 Rocky Mtn. Min. L. InSt. 6A-1, 6A-11 to 6A-12 (2011).

95. See Robert Keiter \& Kristin Lindstrom, Lessons From Nine Mile Canyon: Achieving Consensus Over Energy Development on the Public Lands, 57 Rоску Mtn. Min. L. Inst. 3-1, 3-20 (2011) ("Originally, [the operator] had planned to use traditional extraction techniques of 8 well pads per section, but the new technology enabled it to drill 16 or more wells from a single pad."). 
and convey hydrocarbons to market. Reducing roads and pipelines further minimized ground disturbance.

The statistically significant reduction in surface disturbance associated with O\&G development that we observed may, therefore, have more to do with technology maturation than NEPA. That said, NEPA undoubtedly creates a forum for the public to demand consideration of emerging technologies and for agencies to evaluate the viability of impact reducing technologies. In fact, several EISs included alternatives emphasizing directional drilling and consolidated well pads that were developed in response to public comments. ${ }^{96}$ It, therefore, appears that NEPA may provide an environmental benefit by hastening the deployment of environmentally preferable technologies.

It is unclear whether O\&G operators would have transitioned to consolidating wells on a single pad as rapidly as they have absent NEPA. ${ }^{97}$ Perhaps comparing the rate of emergent technology adoption for projects subject to NEPA against the rate of adoption for projects where NEPA does not apply (such as projects occurring on state or private land) would provide some insight into this question. However, at a minimum, we can say that NEPA provided the public with an opportunity to evaluate the feasibility of alternative technology. As such, NEPA represents an important mechanism for accelerating adoption of emergent technologies that result in reduced environmental impacts.

\section{E. Alternatives and Impact Reduction}

Given our limited sample size $(n=13),{ }^{98}$ our results regarding the effect of the number of alternatives considered on impact reductions should be considered preliminary in nature. However, our analysis indicates that consideration of four or more alternatives does result in greater impact

96. Bureau of Land Mgmt., U.S. Dep't of the Interior, Record of Decision for the Gasco Energy Inc. Uinta Basin Natural Gas Development Project 11-12 (2012) ("[The Agency Preferred Alternative] was developed after the public comment period on the Draft EIS . . . . Surface impacts were reduced by requiring directional drilling .... [T] his alternative was developed as a result of public comment . . .."); Letter from Bill Barrett Corporation, to U.S. Bureau of Land Management (Feb. 24, 2010) (on file with author) (explaining that, in part because of "a significant amount of time discussing the project with other stakeholders and reviewing public comment[,]" the company decided to reduce the number of wells and well pads in a new alternative); Bureau of Land Mgmt., U.S. Dep't of the Interior, Northern San Juan Basin Coal Bed Methane Project Record of Decision 3 (2007) ("I am selecting Alternative 7, with the identified modifications and required mitigation measures, because it most effectively addresses the issues surfaced during the extensive public input process while honoring the lease rights held by the proponents.") (emphasis added).

97. Operators would likely prefer to use traditional vertical wells under most circumstances as " $[\mathrm{t}]$ here is lower cost and risk by drilling vertically. Reserves often can be captured adequately with vertical wellbores. When pumping is required to produce the oil, maintenance costs are lower in vertical wellbores [as compared to directional].” Bureau of Land Mgmt., U.S. Dep't of the Interior, Final Environmental Impact Statement for the Final San Juan National Forest and Proposed Tres Rios Field Office Land and Resource Management Plan 491 (2015) ("Directional drilling techniques can be particularly helpful in environmentally sensitive or culturally rich areas ... [however] these benefits are offset by the incremental increase in both cost (approximately 20\%) and operational risk associated with drilling these more complex boreholes.").

98. As mentioned, the More Alternatives Group had nine EISs and the Fewer Alternatives Group had four EISs. Supra Part IV.E. reduction than consideration of three or fewer alternatives. The More Alternatives Group had statistically significant greater reductions in environmental impact than the Fewer Alternatives Group for six of the thirteen environmental indicators. Despite the preliminary nature of this finding, it appears that evaluating more than three alternatives can improve impact reduction. Nevertheless, these reduced environmental impacts appear to come at the cost of increased EIS preparation time, with EISs considering three or fewer alternatives being completed 312 days sooner than those that considered four or more alternatives.

These reductions appear to be independent of the relationship we observed between project magnitude and number of alternatives considered. Our results indicate that the number of alternatives considered by an agency is related to the magnitude of the proposed project. For example, agencies are likely to consider more alternatives for projects with a greater potential for surface impacts. Based on this relationship, one might conclude that differences in impact reduction are simply the result of different project sizes, meaning the More and Fewer Alternatives groups are equally effective at reducing impacts but the overall impact reduction is different because there are more impacts to be reduced for the More Alternatives Group.

However, if this conflation were true and initial project size, not the number of alternatives considered, was the true cause of the difference in impact reduction, then we would expect the percentage of total impact reduction for the More and Fewer Alternatives Groups to be roughly equal. However, impact reductions for the More Alternatives Group greatly exceeded those of the Fewer Alternatives Group, as measured by the percentage of the initial proposed impact, for seven of the thirteen impacts, with one impact being roughly equal. Thus, initial project size alone does not explain the difference in impact reduction between the two groups.

Although preliminary, these results are intuitive. Consideration of more alternatives indicates a more thorough review. When an agency considers three or fewer alternatives, the agency may have insufficient information regarding available options and the associated tradeoffs.

One may argue that some EISs involve straightforward proposals that do not necessitate a significant range of alternatives. However, as discussed, ${ }^{99}$ since EISs are required for less than $1 \%$ of projects evaluated under NEPA, ${ }^{100}$ and as these projects have already been found to have impacts that are environmentally significant, ${ }^{101}$ there appears to be little reason to severely restrict the scope of alternatives in an EIS.

\section{Conclusions and Recommendations}

Based on our review of O\&G projects within a four-state region, NEPA compliance does appear to produce final decisions that are substantially less impactful on the environment when compared to initially proposed projects. Impact reduc-

99. Daniel R. Mandelker, NePA Law and Litigation $\$ 11: 1$ (2d ed. 2014).

100. U.S. Gov't Accountability Office, supra note 6, at 8.

101. See 43 U.S.C. $\$ 4332(2)(C)$ (2012); 40 C.F.R. $\$ 1502.3$ (2014). 
tions occur primarily between the draft EIS and final EIS stages of the NEPA process, with minor reductions occurring between the final EIS and ROD. While reductions may be partially attributable to legal requirements external to NEPA (such as Clean Air Act, Clean Water Act, or Endangered Species Act requirements or intervening economic and technological factors), external factors alone do not adequately explain impact reductions.

This Article also found that the number of alternatives considered within an EIS affects both the magnitude and proportion of impact reduction. EISs that consider a broader range of alternatives are more effective at reducing environmental impacts. We, therefore, encourage federal agencies to include a robust range of alternatives in their EISs and to use the alternative development and evaluation process to determine whether emergent technologies can reduce environmental impacts without severely impacting project cost or viability.
In light of these findings, we also urge caution when considering proposals to streamline the EIS process, because streamlining efforts may reduce NEPA's tangible benefits. We note that aggressive EIS timelines could, at least in theory, hinder the impact analysis and, in so doing, make EISs more susceptible to legal challenge. Court-ordered EIS supplementation would almost certainly negate any benefits of expediting proposals.

We hope that this first attempt at quantifying the environmental efficacy of NEPA will engender a productive debate on the question of NEPA reform. We acknowledge that the limited scope of our analysis may restrict the applicability of our results and the generalizations that can be drawn from them. However, even assuming that intervening considerations are significant contributing causal factors in NEPA impact reduction, there is little doubt that NEPA leads to less environmentally harmful decisions and that it does so without a dramatic reduction in economic benefits. 